\title{
Research on the Positive Effect of Improving the Quality of FDI on Improving Environmental Pollution
}

\author{
Henan Zhao \\ International College of Zhengzhou University, Zhengzhou, China
}

\begin{abstract}
Based on the theories of "pollution refuge" and "pollution halo", this paper analyzes the relationship between FDI quality and environmental pollution by constructing FDI quality index system, using the data of 30 provinces and cities in China from 2007 to 2019 and using ordinary panel regression and threshold regression, and concludes: The improvement of FDI quality can improve the environmental pollution to a certain extent, and there is regional difference, the eastern and central regions are more significant than the western regions; The threshold regression results with $\mathrm{RD}$ as the threshold variable show that the impact of FDI quality on the environment will be more significant with the increase of R\&D investment, indicating that the country should strive to improve the quality level of FDI.
\end{abstract}

Keywords: FDI Quality; "Pollution Shelter"; "Pollution Halo"; Threshold Regression.

\section{Introduction}

Since the reform and opening up, China's comprehensive strength has improved significantly and its attraction to foreign direct investment has gradually increased. The scale of foreign investment in China has grown from zero to large, ranking first among developing countries for many years in a row. In 2002, the scale of Foreign direct investment in China surpassed that of the United States for the first time and ranked first in the world.FDI has made an indelible contribution to China's economic development as a multi-dimensional combination of capital, technology and marketing.However, in the context of globalization, the transfer of global manufacturing center is accompanied by the transfer of pollution.According to data, China's heavily polluted cities are mainly concentrated in The Beijing-Tianjin-Hebei region, central China and North China, where investment is relatively large.For example, in 2019, Beijing, Tianjin and Chongqing actually utilized FDI of us $\$ 13.5$ billion, US \$32.6 billion and US \$12.3 billion respectively, while their $\mathrm{PM}_{2.5}$ The average annual concentration level has exceeded the standard value, which indicates that there may be a certain correlation between FDI and environmental pollution in China [1].

According to the above problem, this article is based on our country's 30 provinces except Tibet in 2007-2019 data, innovative building FDI quality system and through the fixed effect panel regression, the relationship between the quality of FDI and environment pollution research, at the same time establish a threshold regression model, further analysis of the nonlinear relationship between FDI quality and environmental pollution, It provides a direction for our future policy making.

\section{Literature Review and Research Hypothesis}

The impact of international trade and transnational investment on environmental pollution is a classic study in economics. Based on this, there are two different views in the world, namely "pollution sanctuary" and "pollution halo".

The "pollution haven" hypothesis [2] It was first proposed by economists Copeland and Taylor. It refers to the phenomenon that developed countries transfer high-polluting industries to developing countries in order to reduce environmental pollution, making the latter become a refuge.Kennedy pointed out that under the condition of free trade, countries will ease environmental regulations to enhance industrial competitiveness[3]. There are also many studies based on "pollution refuge" in China. Wei Long and Pan An's study based on panel data of 285 prefecture-level cities in China and adopted GMM instrumental variable method to reach the conclusion that FDI utilization aggravates environmental pollution to some extent, and there is heterogeneity between resource-based cities and 
non-resource-based cities [4]. Through the ARDL-ECM model, Zhang Wenai et al. conducted indepth discussion on the impact of FDI on the environment of the whole country and samples divided into eastern and western regions, verified that FDI had a significant negative effect on environmental pollution in the short term and acknowledged the existence of pollution shelters [5]. Based on the establishment of static and dynamic models, Li Kai and Qi Shaozhou estimated CO in 30 provinces of China 2 Based on emissions, it is found that the impact of trade opening on China's environment is negative, and the "bottom line race" effect is significant [6]. Zhang Kuan investigated FDI from the industry level and found that FDI exacerbated $\mathrm{CO}_{2}$ Important factors in the conclusion [7]. From the above research, we can draw the following hypothesis.

Hypothesis 1: FDI will bring "pollution refuge" effect

The "pollution halo" is the opposite of a "pollution sanctuary", in which developed countries can mitigate pollution in host countries to some extent through spillover effects.Based on this, there are many relevant researches in China. Under the guidance of Copeland and Taylor models, Zhou Jieqi et al. believed that FDI could improve haze pollution through technology spillover effect after comprehensive consideration, which is similar to the view of "pollution halo"[8]. Huo Weidong et al. innovatively subdivided FDI spillover effect and concluded that innovation effect would change at different stages of economic development. When ecological technology spillover dominated, "pollution halo" could be satisfied [9]. Zhang Qianqian creatively studied the impact of FDI on environmental quality under environmental regulations from the industrial level. In general, under the effect of environmental regulations, FDI has a positive effect on the improvement of environmental pollution to a certain extent [10]. Through the relevant research shows that domestic technology level, as a measure of the quality of FDI factors such as environmental regulation in the ease of FDI on the environment pollution of conduction effect, but the existing research literature, mostly focus on the number of levels of FDI, while in this paper, breaking through any limits from original from the level of quality to study relationship between FDI and environment pollution.Based on the above, the second hypothesis is obtained.

Hypothesis 2: The improvement of FDI quality will improve environmental pollution

\section{Models, Variables, and Data}

\subsection{Modeling}

The model in this paper is based on the model set by Bai Junhong and Lv Xiaohong (2015) [11], as follows:

$$
\operatorname{lnEPI} \mathrm{it}_{\mathrm{i}}=\mathrm{FQ} \beta_{0}+\beta_{1 \mathrm{it}}+\beta_{2} \text { Control }_{i t}+\mu_{i}+\delta_{t}+\varepsilon_{i t}
$$

In the above formula, EPI (Environmental Pollution Index) represents Environmental Pollution degree Index, FQ refers to FDI quality, subscripts I and T represent provinces and periods respectively, and Control represents Control variables. The control variables selected in this paper include regional economic development level (EC), human capital (HC), industrial structure (IS) and R\&D intensity (RD). $\mu_{i}$ Is the individual effect that does not change with time, is the time effect that changes with time, is the error term, and. $\delta_{t} \varepsilon_{i t} \varepsilon_{i t} \sim \operatorname{iid}\left(0, \sigma^{2}\right)$

\subsection{Description of Variables}

(1) Degree of environmental pollution

There are many ways to measure environmental pollution. One is to measure the emission of core pollutants [11]. The other is to select comprehensive indicators [12]. In this paper, the latter is adopted, and the three indicators of industrial waste water discharge, solid waste discharge and exhaust gas discharge are used to measure solid, liquid and gas discharge, and the entropy method is used to combine the three indicators into environmental pollution degree index, which is used as the explained variable in this paper. 
(2) The quality of FDI

FDI quality is the core explanatory variable of this paper.The United Nations Conference on Trade and Development defines high-quality FDI as only the FDI that can promote the technological improvement and enhance the competitiveness of the host country.In order to accurately show the quality of FDI, this paper measures the quality of FDI from three aspects: scale of FDI (SC), technical level of FDI (TC), and export drive of FDI (EX). The above three indicators are described as follows:

Scale of Foreign investment (SC).In this paper, "the actual use of FDI/GDP" is used to measure, and the current exchange rate is used to convert the actual use of FDI into RMB in the calculation.

Technical level (TC).Technological level is an important factor to measure the quality of foreign investment. The improvement of technological level can promote the improvement of production efficiency of foreign-funded enterprises and promote the development of host countries through technological spillover effect.In this paper, THE $r \& d$ spillover degree obtained from FDI path is used to represent FDI quality.

Exit pull (EX).FDI can expand development opportunities and bring advanced technologies to host countries.In this paper, the export driving force of FDI is represented by the export of foreign-funded enterprises/total export of each region.

\subsection{Control Variables}

In order to avoid errors in research results due to too few variables and omissions, the following four control variables are selected in this paper.

Level of economic development (EC). According to the environmental Kuznets curve, there is an inverted U-shaped relationship between environmental pollution and per capita GDP of a country. It is common for most developing countries to develop their economy at the expense of the environment. This paper adopts regional GDP to reflect regional economic development level and takes logarithm to reduce the impact of fluctuations.

Human capital (HC). Human capital can reflect the quality level of residents, the higher the human capital, the greater the development potential.In this paper, the human capital level of each region is represented by the weighted average of the student status and the proportion of the total population in each period. The formula is as follows:

$$
\begin{array}{r}
\mathrm{H}_{\mathrm{i}}=\mathrm{t}_{\mathrm{t}_{\text {op }}}^{\text {hig }_{\text {it }}} * \\
\frac{\text { sec }_{\text {it }}}{\text { pop }_{\text {it }}} \frac{\text { col }_{\text {it }}}{\text { pop }_{\text {it }}}
\end{array}
$$

In the above formula, $\mathrm{H}_{\mathrm{it}}$ Refers to the human capital situation of province $\mathrm{I}$ in $\mathrm{t}$ years, hig $_{i t} \sec _{i t}$ Col $_{i t}$ pop $_{i t}$.

Respectively, the number of students in senior high schools, secondary vocational schools and institutions of higher learning in PROVINCE I in t years and the total population of the region;12 and 16 are weighted by years of education.

Industrial structure (IS). The secondary industry has a more important impact on the environment. This paper adopts the industrial output value/regional GDP to represent the industrial structure.

$\mathrm{R} \& \mathrm{~d}$ investment (RD).RD investment reflects a region's emphasis on scientific research.If part of the $\mathrm{r} \& \mathrm{~d}$ investment is used to develop environmentally friendly technology, it will be beneficial to the improvement of environmental pollution. This paper directly uses the index of RD investment intensity in China Statistical Yearbook.

\subsection{The Data Shows That}

Based on data availability, this paper uses data from 2007 to 2019 from 30 provinces in China as samples.The data come from China Statistical Yearbook, Local Statistical Yearbook, etc.At the same time, based on the actual differences in China, the above samples are divided into three regions: 
eastern, central and western.The eastern region covers 11 provinces and cities, including Beijing, Tianjin, Hebei, Shanghai, Jiangsu, Zhejiang and Guangdong.The central region covers eight provinces, including Shanxi, Jilin, Heilongjiang, Henan, Hubei and Hunan. The western region covers 11 provinces and regions, including Chongqing, Sichuan, Shaanxi, Yunnan, Guizhou, Ningxia and Inner Mongolia.

\section{The Empirical Analysis}

(1) Full sample regression results and heterogeneity analysis

The data in this paper are balanced panel data, and after Hausman's test, it is believed that the fixed-effect model should be adopted for regression in this paper. Table 1 shows the regression results of the whole country as well as the three regions of eastern, central and western China.

Table 1. Linear regression estimation results

\begin{tabular}{|c|c|c|c|c|}
\hline variable & The national & In the east & In the middle & In the west \\
\hline TC & $* *(0.060-0.076)$ & $0.106(0.616)$ & $* *(0.318-1.793)$ & $1.054(1.092)$ \\
\hline SC & $0.151 *(0.052)$ & $0.926 *(0.061)$ & $0.731(0.822)$ & $0.129 *(0.079)$ \\
\hline EX & $0.156 *(0.010)$ & $* *(0.099-0.320)$ & $0.413(1.37)$ & $0.002(1.039)$ \\
\hline EC & $0.152 *(0.029)$ & $0.176 *(0.108)$ & $0.738(1.43)$ & $0.584 * * *(0.031)$ \\
\hline HC & $* *(0.1200 .571)$ & $0.969 * * *(0.094)$ & $* *(0.0030 .258)$ & $* *(0.061-2.203)$ \\
\hline IS & $2.782 * * *(0.007)$ & $* *(0.0182 .245)$ & $* *(0.0011 .245)$ & $* *(0.0896 .409)$ \\
\hline RD & $* *(0.0124 .324)$ & $* *(0.00515 .280)$ & $* *(0.13710 .367)$ & $2.461(0.074)$ \\
\hline Constant term & $* *(0.00015 .245)$ & $14.824 *(0.006)$ & $* *(0.01312 .607)$ & $6.436(0.509)$ \\
\hline The F value & 67.32 & 89.87 & 60.53 & 33.08 \\
\hline R squared & 0.245 & 0.640 & 0.354 & 0.507 \\
\hline
\end{tabular}

Note: $* * *, * *$ and $*$ are significant at $1 \%, 5 \%$ and $10 \%$ levels respectively; The numbers in parentheses indicate the probability of significance.

The following analysis can be made from Table 1.First of all, the influence coefficient of FDI quality represented by technology, scale and export is significantly negative, which means that when the technological level is improved, the scale of foreign investment is expanded and export is increased, it is conducive to the reduction of environmental pollution and FDI plays a role in reducing pollution.This may be because the spillover effect of FDI improves the competitiveness of China's industry, and with the expansion of foreign investment, the advantage of scale efficiency can be brought into play, contributing to the reduction of China's environmental pollution.

From the regional regression results, it can be seen that there are certain differences among the eastern, central and western regions.From the perspective of the eastern region, the impact of FDI quality on the environment measured by FDI scale and export is similar to that of the national results, but the impact degree is significantly increased, which indicates that the FDI scale and export volume in the eastern region are higher than the national average level, which is closely related to the policy orientation of the eastern region.However, the impact of FDI quality measured by technological level on environmental pollution is not significant, which may be because the gap between the development level of eastern China and that of foreign countries is narrowed, and the spillover effect is no longer significant.

From the point of the central and western regions, with the scale to measure the quality of FDI to the pollution of the environment influence is not significant in the central region, and in the western region is significantly negative, although may be due to the backward western regions, but in the western region of low labor costs, abundant energy, tend to be in the western region in recent years foreign investment, see from the data collection, The scale of foreign investment in Yunnan, Sichuan, Chongqing and other places has been on the rise in recent years, which helps to play the role of FDI in promoting environmental pollution.FDI quality measured by technological level has a significant negative impact on environmental pollution, which indicates that there is still a gap between the 
central region and the national average level. Therefore, the technological level of the central and western regions should be gradually improved to realize the coordinated development of China's economy.

From the regression results of control variables, the regional economic development level is significantly negative in the whole country and the eastern region, but significantly positive in the western region. This shows on the one hand that there is a significant gap between the central and western regions of China and the eastern region, and on the other hand, the western region still sacrifices the environment for economic development.Human capital and $\mathrm{r} \& \mathrm{~d}$ spending in the country and the east, the central region were significantly positive, but a negative significant in the western region, the cause of this difference might be due to the eastern and central regions of the human capital and technology research and development has achieved a certain degree of development, and because the policy and development under the pressure, more investment in east and central regions, To a certain extent, the investment in pollution control is compressed, while the western region pays less attention to technological development and has a small pollution base. Therefore, human capital and $R \& D$ investment can achieve better results in environmental pollution control in the western region.In terms of industrial structure, it is significantly positive in the whole country as well as in the eastern, central and western regions, which shows that the excessive proportion of secondary industry has a negative impact on the environment.

The above analysis of FDI quality is mainly measured from the three aspects of scale, export and technical level. Then, SPSS software is used for factor analysis of the three indicators of FDI quality, and the comprehensive factor score is obtained, which is used as the total FDI quality (FQ) index for regression. The results are as follows:

Table 2. Linear regression estimation results of FQ

\begin{tabular}{|c|c|c|c|c|}
\hline variable & The national & In the east & In the middle & In the west \\
\hline FQ & $* *(0.015-0.051)$ & $* *(0.098-0.152)$ & $0.055 *(0.052)$ & $0.339(0.381)$ \\
\hline EC & $* *(0.083-0.170)$ & $* *(0.343-0.415)$ & $* *(0.016-0.027)$ & $* *(0.0070 .329)$ \\
\hline HC & $0.647 *(0.022)$ & $0.737 * * *(0.057)$ & $0.356(0.530)$ & $0.356(0.53)$ \\
\hline IS & $2.869 * * *(0.645)$ & $4.700 * * *(0.457)$ & $* *(0.4042 .591)$ & $4.559 * * *(0.078)$ \\
\hline RD & $4.411 * * *(0.005)$ & $* *(0.31613 .161)$ & $* *(0.032-0.614)$ & $15.532 * * *(0.422)$ \\
\hline Constant term & $* *(0.0009 .340)$ & $14.892 * * *(0.000)$ & $9.176 *(0.000)$ & $4.008(0.422)$ \\
\hline The F value & 67.51 & 38.65 & 74.31 & 49.28 \\
\hline R squared & 0.266 & 0.534 & 0.519 & 0.108 \\
\hline
\end{tabular}

Note: the figures in brackets are the probability of significance; $* * *, * *$ and $*$ are significant at the level of $1 \%, 5 \%$ and $10 \%$ respectively

Table 2 shows that the impact of FDI quality on environmental pollution is significantly negative in the national sample, showing that the improvement of FDI quality has an impact on the reduction of environmental pollution to a certain extent.In terms of regions, this effect is more significant in eastern and central regions than in western regions, which can reflect the reality that the quality of foreign investment in eastern and central regions is relatively high, and verify hypothesis 2 that the improvement of FDI quality can improve environmental pollution.

(2) Further explore the non-linear relationship between FDI quality and environmental pollution

Threshold model, first proposed by Hansen, is mainly used to explain the nonlinear relationship between samples and is widely used.From the previous analysis, we can see that FDI quality has a certain impact on environmental pollution, and there are differences among different regions. By analyzing the differences among the three regions in China, we believe that this may be related to $r \& d$ investment in each region. That is, when $r \& d$ investment reaches a certain threshold value, the local utilization capacity of FDI can be improved to better play the inhibitory effect of the improvement of FDI quality on environmental pollution. Then does this threshold exist?The following paper further discusses the relationship between FDI quality and environmental pollution through panel threshold regression. 
First of all, it is assumed that there is only a single threshold value in the problems discussed in this paper. As, the $\mathrm{r} \& \mathrm{~d}$ investment intensity in the control variable is taken as the threshold variable to test whether the change of its intensity will affect the effect of FDI quality on environmental pollution [14]. The model is established as follows:

$$
\begin{aligned}
\operatorname{lnEPI}= & \beta_{0}+\beta_{11} \mathrm{FQ}_{\mathrm{it}} \times \mathrm{I}\left(\mathrm{q}_{\mathrm{it}} \leq \gamma\right)+\beta_{12} \mathrm{FQ}_{\mathrm{it}} \times \mathrm{I}\left(\mathrm{q}_{\mathrm{it}}>\gamma\right) \\
& +\beta_{2} \text { Control }_{i t}+\mu_{i}+\delta_{t}+\varepsilon_{i t}
\end{aligned}
$$

Among the above models, EPI ${ }_{i t} I s$ environmental pollution index, is the explained variable of this paper, FQitIs the core explanatory variable of this paper, and refers to FDI quality, QitIs the threshold variable, refers to $\mathrm{r} \& \mathrm{~d}$ intensity $(\mathrm{RD})$ in the paper, is the threshold value, $\mathrm{I}(\cdot)$ is the indicator function, refers to when and, the influence coefficient of FDI quality on environmental pollution) is the random interference term. $\gamma \beta_{11}, \beta_{12} q_{i t} \leq \gamma q_{i t}>\gamma, \varepsilon_{i t} \sim i i d\left(0, \sigma^{2}\right.$ Table 3 shows the test results of the existence of the threshold effect and the specific threshold quantity through repeated sampling for 400 times by Bootstrap method:

Table 3. Test results of threshold effect of R\&D investment intensity

\begin{tabular}{|c|c|c|c|c|c|}
\hline & $\begin{array}{c}\text { The F } \\
\text { value }\end{array}$ & P values & threshold & $\begin{array}{c}\text { Lower 95\% confidence } \\
\text { interval }\end{array}$ & $\begin{array}{c}95 \% \text { confidence upper } \\
\text { bound }\end{array}$ \\
\hline $\begin{array}{c}\text { Single } \\
\text { threshold }\end{array}$ & $20.06 * *$ & 0.018 & 0.440 & 0.137 & 0.805 \\
\hline $\begin{array}{c}\text { Double } \\
\text { threshold }\end{array}$ & 7.58 & 0.369 & 0.370 & - & - \\
\hline Three threshold & 5.88 & 0.623 & 1.190 & - & - \\
\hline
\end{tabular}

Note: $* * *, * *$ and $*$ are significant at $1 \%, 5 \%$ and $10 \%$ levels respectively

It can be seen from Table 3 that the threshold effect exists and is a single threshold with a threshold value of 0.440 . Therefore, the regression results of $R \& D$ investment intensity as the threshold are further shown in Table 4.

\begin{tabular}{|c|c|c|}
\hline variable & Estimated coefficient & A confidence interval \\
\hline FQ1 & $\begin{array}{c}0.079 * * \\
(0.038)\end{array}$ & {$[0.348,0.510]$} \\
\hline FQ2 & $\begin{array}{c}0.306 * * \\
(0.042)\end{array}$ & {$[0.150,0.085]$} \\
\hline $\mathrm{EC}$ & $\begin{array}{c}0.0464 * \\
(0.034) \\
\end{array}$ & {$[0.137,0.437]$} \\
\hline $\mathrm{HC}$ & $\begin{array}{c}0.183 * * \\
(0.05)\end{array}$ & {$[0.735,0.369]$} \\
\hline IS & $\begin{array}{c}3.140 * * * \\
(0.946)\end{array}$ & {$[2.250,4.300]$} \\
\hline $\mathrm{RD}$ & $\begin{array}{c}3.245 * * * \\
(0.904)\end{array}$ & {$[2.336,5.314]$} \\
\hline Constant term & $\begin{array}{l}1.37 * * \\
(0.782)\end{array}$ & {$[1.902,0.338]$} \\
\hline $\begin{array}{l}\text { F (test) } \\
(\mathrm{p})\end{array}$ & \multicolumn{2}{|c|}{$\begin{array}{l}70.85 \\
(0.000)\end{array}$} \\
\hline
\end{tabular}

Table 4. Regression results of single threshold effect of R\&D investment

Note: $* * *, * *$ and $*$ represent significance levels at $1 \%, 5 \%$ and $10 \%$ respectively. Standard error is in brackets.

As can be seen from Table 4, taking the threshold value of 0.440 as the boundary, when the R\&D investment intensity is less than 0.440 , FDI quality has a significant reverse impact on environmental pollution, and the impact coefficient is $7.9 \%$, that is, when FDI quality increases by one unit, 
environmental pollution decreases by about $7.9 \%$. When the $\mathrm{r} \& \mathrm{~d}$ investment intensity is greater than 0.440 , the influence coefficient of FDI quality improvement on environmental pollution reaches $30.6 \%$.It means that with the increase of $R \& D$ investment intensity, the effect of FDI quality also increases, reflecting the non-linear relationship between FDI quality and environmental pollution.

\section{Robustness Test}

In order to make the conclusion more accurate, this paper adopts the method of shortening the time window to conduct robustness test. The samples used in this paper are the data of 30 provinces and cities in China from 2007 to 2019. We shorten the time span to 10 years from 2010 to 2019, and the results are as follows:

Table 5. Linear regression estimation results of FQ: 2010-2019

\begin{tabular}{|c|c|c|c|c|}
\hline variable & The national & In the east & In the middle & In the west \\
\hline FQ & $* *(0.012-0.038)$ & $0.067 * * *(0.007)$ & $* *(0.011-0.017)$ & $0.122(0.130)$ \\
\hline EC & $* *(0.009-0.047)$ & $0.092 *(0.034)$ & $0.041 *(0.016)$ & $0.024(0.170)$ \\
\hline HC & $0.659 *(0.018)$ & $1.385 * * *(0.126)$ & $1.316 * * *(1.420)$ & $0.707(1.134)$ \\
\hline IS & $3.306 * * *(0.588)$ & $* *(0.3316 .160)$ & $1.683 *(0.174)$ & $4.054 * *(0.039)$ \\
\hline RD & $4.443 * * *(0.458)$ & $14.009 * * *(0.237)$ & $* *(0.330-0.788)$ & $13.397 * *(0.022)$ \\
\hline Constant term & $* *(0.0018 .211)$ & $13.704 * * *(0.000)$ & $7.273 * * *(0.153)$ & $3.343(0.097)$ \\
\hline The F value & 70.85 & 37.55 & 90.76 & 47.86 \\
\hline R squared & 0.447 & 0.502 & 0.423 & 0.468 \\
\hline
\end{tabular}

Note: $* * *, * *$ and $*$ are significant at the level of $1 \%, 5 \%$ and $10 \%$ respectively, and the numbers in brackets are not significant probability.

The results in Table 5 are basically consistent with the previous conclusions. In the whole country, FDI quality has a significant negative impact on environmental pollution, and the impact is more significant in the eastern region.At the same time, from the perspective of control variables, compared with Table 5, the impact of human capital on environmental pollution in the central region from 2010 to 2019 has changed, showing a positive and significant relationship, indicating that in recent years, the talent training in the central region has achieved significant results, and the gap between the central region and the eastern region has gradually narrowed. After robustness test, the conclusion is basically consistent with the above, that the improvement of FDI quality can indeed play a helpful role in alleviating environmental pollution.

\section{Conclusions and Policy Recommendations}

Based on the controversy of "pollution shelter" and "pollution halo", this paper studies the FDI quality index system and conducts panel regression and threshold regression for the data of 30 provinces and cities in China in 13 years, and some basic conclusions can be obtained. On the whole, the improvement of FDI quality has a promoting effect on environmental pollution to some extent, but there are differences among regions. This effect is more significant in the central and eastern regions, but not in the western regions. Secondly, for the eastern region, the FDI quality index measured by size and export is significantly negative and higher than the national average, but the index measured by technology is not significant. For the central and western regions, FDI quality index measured by the size was not significant in the central region, and in the western region is significantly negative, FDI quality index measured by the technology level in the central region is significantly negative, in the western region is not significant, but a negative correlation, indicating that the central and western regions of foreign technical level is still relatively backward. Finally, threshold regression is conducted in this paper. The results show that there is an obvious single threshold effect on the impact of R\&D investment intensity on environmental pollution. With the 
increase of R\&D investment, the promoting effect of FDI quality on environmental pollution is more obvious, which further verifies the existence of "pollution halo".

China recently put forward the goal of carbon neutrality and carbon peak, which reflects the high importance of environmental governance. According to the research and practice of this article, we can put forward the following Suggestions: first, based on the east central and western regions in our country economic development level, technology level and other differences, countries should be targeted foreign policy in the region, in every region to develop more targeted management and guidance, to foreign capital and give full play to the role of the lower environmental pollution; Secondly, after analysis, we can see that regional differences are still significant. In the future, we should accelerate the implementation of regional collaborative development strategy, gradually increase $r \& d$ investment in central and western regions, make better use of the benefits brought by technology spillover, and abandon the tradition of developing economy at the expense of the environment. Third, China should encourage the entry of high-quality foreign investment and raise the entry threshold for foreign investment.

\section{References}

[1] Wang Feng, He Jingze, Shi Dongjie. Foreign direct investment, technological level and urban haze pollution: Based on dynamic spatial panel data analysis of 276 prefectural cities in China [J]. Journal of Chongqing University (Social Sciences).

[2] Copeland B R, Scott T M. North-South Trade and the Environment[J]. Quarterly Journal of Economics, 1994 (3):755-787. Learning edition): 1-15 [2022-02-05]. http:// kns. cnki. net/kcms/ detail/50. 1023. C. 20211012.1407.002.html.

[3] Kennedy P W. Equilibrium Pollution Taxes in Open Economies with Imperfect Competition - Science Direct [J]. Journal of Environmental Economics and Management, 1994, 27( 1):49-63.

[4] Wei Long, Pan An. Do export trade and FDI aggravate environmental pollution in resource-based cities? --empirical study on panel data of 285 prefectural cities in China [J]. Journal of natural resources, 2016, $31(01): 17-27$.

[5] Zhang Wenai, Luo Runwan. The Environmental Effect of FDI: "Pollution halo" or "Pollution Paradise"?- based on empirical test panel ARDL - the ECM model [J/OL]. Journal of chongqing university (social science edition) : 1-19 [2022-02-05]. http://kns.cnki.net/kcms/detail/50.1154.C.20210719.1745.014 .html.

[6] li kai, qi shaozhou. Trade opening, economic growth and carbon dioxide emissions in China [J]. Economic research journal,2011,46(11):60-72+102.

[7] Zhang Kuan. Does FDI increase CO_2 emissions in China's manufacturing industry?[J]. Journal of financial theory research, 2019 (6) : 88-102. The DOI: 10.13894 / j.carol carroll nki jfets. 2019.06.009.

[8] Zhou Jieqi, LIANG Wenguang, ZHANG Ying, Han Ying. Foreign Direct Investment, environmental regulation and haze pollution: Theoretical analysis and experience from China [J]. Journal of Beijing institute of technology (social science edition), 2019, 21 (01) : 37-49. DOI: 10.15918 / j.j bitss 1009-3370. 2019. 5296.

[9] Huo Weidong, Li Jiefeng, Chen Ruoyu. Green development and FDI's environmental effect: From "pollution paradise" to "pollution halo" data demonstration [J]. Science of Finance and Economics, 2019 (04): 106-119.

[10] Zhang Q Q. The impact of FDI on environmental quality under environmental regulation: Based on the threshold effect of pollution intensive industry classification [J]. Journal of henan university (social science edition), 2020, 60 (03) : 93-99. The DOI: 10.15991 / j.carol carroll nki 411028.20200506.011.

[11] Bai Junhong, Lv Xiaohong. The improvement of the quality of FDI and China's environmental pollution [J]. Journal of international trade issues, 2015 (8) : 72-83. The DOI: 10.13510 / j.carol carroll nki. Jit. 2015.08.008.

[12] Wang Xiaoling, He Feng, Zhu Zhaojun. FDI of beijing-tianjin-hebei environmental quality impact study [J]. Journal of financial research, 2019 (9) : 45 to 52. DOI: 10.19654 / j.carol carroll nki cjwtyj. 2019. 09. 006. 
[13] Huang T. Research on the impact of foreign direct investment quality on China's green economic growth [D]. Xinjiang university, 2020. DOI: 10.27429/, dc nki. Gxjdu. 2020.000567.

[14] Dong Xiangyu, Zhao Shouguo. Research on nonlinear relationship between Economic growth and leverage ratio in China: Based on threshold regression analysis of Manufacturing panel Data [J]. Systems engineering-theory \& practice,2020,40(02):343-354.

[15] Dan-lin li. Strategy under the perspective of "binary" [N]. The financial times, 2021-06-11 (010). The DOI: 10.28460 / n.c. Nki NJRSB. 2021.002935. 